\title{
POLÍTICA DE FINANCIAMENTO E A EXPANSÃO DA EDUCAÇÃO SUPERIOR NO BRASIL: O PÚBLICO E O PRIVADO EM QUESTÃO
}

\author{
FINANCING POLICY AND THE HIGHER EDUCATION EXPANSION IN BRAZIL: THE \\ PUBLIC AND THE PRIVATE CONCERNED
}

\author{
POLÍTICA DE FINANCIAMIENTO Y LA EXPANSIÓN DE LA EDUCACIÓN SUPERIOR EN \\ BRASIL: LO PÚBLICO Y LO PRIVADO EM CUESTIÓN
}

\section{Vera Lúcia Jacob Chaves ${ }^{1}$}

\begin{abstract}
RESUMO: O artigo analisa o perfil do financiamento para a expansão do ensino superior, visando discutir a parceria público-privada para tanto, nos governos de Lula da Silva e Dilma Rousseff. O estudo parte da tese de que o financiamento da educação superior pública está diretamente relacionado à política de ajuste fiscal do Estado, implementado no Brasil desde 1990, como parte das reformas neoliberais adotadas nos países da América Latina, por orientações dos organismos internacionais, em especial o Banco Mundial, o Fundo Monetário Internacional e a Organização para a Cooperação e Desenvolvimento Econômico. Utilizou-se a metodologia quanti-qualitativa com coleta de fontes documentais e dados do Instituto de Estudos e Pesquisas Educacionais Anísio Teixeira (INEP) e do Orçamento Executado da União, no período de 2003 a 2012. O texto faz uma reflexão sobre a política de financiamento da educação superior pública brasileira estabelecendo relação com a expansão pública e privada desse nível de ensino. O estudo evidenciou que, apesar do crescimento das matrículas no setor público federal, a política de expansão desse nível de ensino tem favorecido o setor privado, por meio de incentivos governamentais, especialmente nos programas PROUNI e FIES. A análise detalhada do orçamento da União, considerando a movimentação entre receitas e despesas, evidenciou a política de ajuste fiscal implementada pelo governo, atingindo diretamente as Universidades públicas federais. Nas conclusões apontamos a necessidade de aumento imediato dos recursos por meio da aplicação de $10 \%$ do Produto Interno Bruto para a educação pública do país.
\end{abstract}

PALAVRAS-CHAVE: Financiamento. Expansão. Público e Privado. Ensino Superior.

ABSTRACT: This article analyzes the financing's profile of higher education expansion, aiming to debate about public-private partnership on financing this education's level during Lula da Silva and Dilma Rousseff governments. The study starts from the thesis that the public higher education's financing it's directly related to State's tax adjustment policy implemented in Brazil since 1990, as part of the neoliberal reforms adopted on the Latin America countries, following the guidance of international bodies, such as World Bank, International Monetary Fund (IMF) and Organization for Economic Cooperation and Development (OECD). The qualitative and quantitative methodology was used, by collecting documental sources and data from Institute of Educational Studies and Researches Anísio Teixeira (INEP) and from Federal Government Implemented Budgetary on term from 2003 to 2012. The text reflects the financing policy of Brazilian public higher education, establishing a relationship with public and private expansion of this education level. The study evinced that despite of the increasing of enrollment in Federal public sector, the expansion policy of this education level has granted the private sector by means of governmental incentives, especially with PROUNI (University For All Program) and FIES (Students Financing Fund) programs. The detailed analyze of the Federal Government budgetary,

\footnotetext{
${ }^{1}$ Doutora em Educação pela Universidade Federal de Minas Gerais. Professora da Universidade Federal do Pará, Belém, PA - Brasil. E-mail: veraluciajacob@gmail.com.

Recebido em: 18/05/2015 - Aprovado em: 16/07/2015.
}

\begin{tabular}{l|l|l|l|l|l|l|} 
(C) ETD -Educ. temat. digit. & Campinas, SP & v.17 & n. 2 & p.427-441 & maio/ago. 2015 & ISSN 1676-2592
\end{tabular} 
considering the transactions between incomes and expenses, a tax adjustment implemented by federal government was evinced, directly hitting the federal public Universities. At the conclusions, we have pointed out the necessity of immediate increase of resources, by means of application of $10 \%$ of the Gross Domestic Product (GDP) for Brazilian public education.

KEYWORDS: Financing. Expansion. Public and Private.

RESUMEN: El artículo propone un análisis sobre el perfil del financiamiento en la expansión de la educación superior con el objetivo de discutir el tema de la asociación público-privada en este nivel de educación, durante los gobiernos de Lula da Silva y Dilma Roussef. Este estudio tiene como principio la tesis de que el financiamiento de la educación superior está directamente relacionada a la política del ajuste fiscal del Estado implementado en Brasil desde 1990, como parte de las reformas neoliberales adoptadas en los países de América Latina por influencia de los organismos internacionales, en especial del Banco Mundial, el Fondo Monetario Internacional y la Organización para la Cooperación y Desarrollo Económico. La metodología utilizada fue la cuantitativa y cualitativa con recopilación de fuentes documentales y datos del Instituto de Estudos e Pesquisas Educacionais Anísio Teixeira (INEP) y del Orçamento Executado da União, en el periodo entre 2003 y 2012. El texto propone una evaluación sobre la política del financiamiento de la educación superior pública brasileña estableciendo una relación con la expansión pública y privada de este nivel de educación. Este estudio mostró que, a pesar del crecimiento de las matrículas en el sector público federal, la política de expansión de este nivel de educación ha beneficiado el sector privado a partir del uso de incentivos del gobierno, especialmente los programas PROUNI y FIES. El análisis detallado del presupuesto de la União, considerando los ingresos y gastos, evidenció que la policita del ajuste fiscal implementada por el gobierno, alcanzando directamente las Universidades públicas federales. En las conclusiones, es apuntada la necesidad de un aumento inmediato de los recursos por medio de la aplicación de 10\% del Producto Nacional Público para la educación pública del país.

PALAVRAS CLAVES: Financiamento. Expansión. Público y privado.

\section{INTRODUZINDO A TEMÁTICA}

Esse artigo tem por objetivo central apresentar os resultados da análise realizada sobre a política de financiamento da educação superior no Brasil, com ênfase para a discussão sobre a parceria público-privada no financiamento desse nível de ensino, nos governos de Lula da Silva (2003-2010) e Dilma Rousseff (2011-2014)i. Compreendemos que tal análise deve estar situada no âmbito global da política educacional em curso no país, na medida em que as mudanças que se evidenciam na política de financiamento estão interligadas à contrarreforma do Estado brasileiro e à crise mundial do sistema do capital.

A tese defendida é a de que as reformas em curso no país objetivam ajustar as ações do Estado para adequá-lo à nova ordem internacional do capital, cuja centralidade fundamenta-se no ajuste fiscal do Estado, com vistas à redução orçamentária para a implementação das políticas sociais. Os reflexos dessas ações na educação superior brasileira manifestam-se por meio da política de cortes de verbas para custeio das Instituições Federais de Ensino Superior (IFES), aliada à concessão de autonomia, por meio do estímulo à busca de recursos externos para a sua sobrevivência (AMARAL, 2003), e adoção de políticas de isenção fiscal ao setor privado, contribuindo para a expansão acelerada desse setor na oferta do ensino superior. A reforma da educação superior brasileira, em curso desde o início do governo de Fernando Henrique Cardoso (1995), tem como centralidade a promoção de 
parcerias entre as instituições públicas e o setor privado. A adoção dessa política é justificada pela necessidade da concentração dos investimentos públicos em áreas de alta relevância econômica, tendo como prioridade "alocar recursos às instituições públicas que tivessem projetos elaborados em parceria com as empresas privadas e fossem voltadas para aplicações comerciais". (OLIVEIRA, 2002, p. 73)

Para o desenvolvimento da pesquisa, utilizamos dados referentes ao investimento em Manutenção e Desenvolvimento do Ensino Superior, feitos pela União no período de 2003 a 2012, com ênfase para os recursos oriundos do Orçamento Geral da União. Utilizamos, também, dados do Instituto Nacional de Estudos e Pesquisas Anísio Teixeira - INEP, referentes ao Censo da Educação Superior, e os investimentos públicos em educação, disponíveis no site desses órgãos.

Para melhor compreensão do estudo, procuramos explicitar alguns elementos centrais da reforma do Estado brasileiro e da política de financiamento da educação superior pública federal implementada no Brasil, objetivando concretizar as seguintes tarefas: a) refletir sobre a crise atual do capitalismo e seus efeitos na implementação das políticas de ajuste neoliberais, em especial no campo das políticas educacionais; b) analisar as consequências dessas políticas no financiamento da educação, com ênfase para a relação público-privada na educação superior.

\section{CRISE E CONTRARREFORMA DA EDUCAÇÃO SUPERIOR BRASILEIRA}

Desde 2008, vivencia-se no mundo capitalista uma crise estrutural que tem repercussões diretas em todo o sistema social, em especial nas políticas sociais, que passaram a ser consideradas como o grande entrave para o crescimento da economia. A defesa de que as regras do mercado devem dar a direção para toda a vida na sociedade, em especial para as políticas sociais, tem provocado um conjunto de contrarreformas, que atinge direitos sociais duramente conquistados pela classe trabalhadora.

Em todo o mundo, as instituições de educação superior foram afetadas por mudanças ocorridas na esfera do trabalho e por um movimento reformista, orientado por organismos multilaterais de financiamento como o Fundo Monetário Internacional e o Banco Mundial. As orientações das reformas educacionais, impostas por esses organismos, têm como fundamento as regras do mercado na gestão e financiamento das políticas públicas. Como receita para superar o déficit público e estabilizar as convulsionadas economias, esses organismos defendem a redução dos custos, o aumento da competitividade, e a formação de recursos humanos mais produtivos. Um dos argumentos utilizados reside na má qualidade dos serviços prestados pelo Estado, ressaltando-se a eficiência dos serviços oferecidos pelo setor privado, e orientados para o lucro. 
O estímulo à competitividade entre as instituições, direcionando-as para o mercado, com a finalidade de contenção dos gastos públicos, passa a ser a tônica das propostas e projetos dos sucessivos governos neoliberais instalados no mundo do capital. Como parte desse movimento, foram adotadas, nas últimas décadas, contrarreformas no sistema educacional que afetaram praticamente todas as universidades e instituições de ensino superior, de forma mais ou menos intensa, mesmo que inseridas em países com economias distintas, e sendo portadoras de histórias e identidades bastante diferenciadas. Essas contrarreformas foram a resposta dada pelos Estados capitalistas às novas demandas da economia global, os novos papéis atribuídos ao Estado, e para atender às recomendações embutidas em relatórios, documentos e empréstimos financeiros dos organismos multilaterais a serviço dos Estados centrais.

No caso brasileiro, entre as principais consequências desse processo, destaca-se a intensa privatização da educação superior, e a implementação do modelo de gestão gerencial nas Universidades públicas. Esse processo provoca mudanças substanciais que adentram o universo acadêmico, segundo a racionalidade capitalista, transformando a organização e o funcionamento das universidades. (CHAVES, 2005)

Como resultado dessa política de privatização do ensino superior, que no caso do Brasil, é reforçada pela falta de incentivos para o crescimento do ensino superior público, por meio da redução drástica dos recursos para as IES públicas, aliada a uma política de arrocho salarial dos trabalhadores dessas instituições, a crise das Universidades públicas acentua-se.

É nesse contexto de crise e de privatização intensa que se tem destacada a necessidade de ampliação do acesso à educação superior. Entre os problemas que estão na origem da crise da universidade brasileira, e que tem contribuído para o comprometimento de seu futuro, destacamos a questão do aumento da demanda de candidatos (acesso) ao ensino superior e a do financiamento.

A demanda de candidatos pelo ensino superior é cada vez maior, na medida em que, segundo dados do Ministério de Educação, na faixa etária de 18 a 24 anos, somente 14,1\% da população frequentava, em 2012, algum tipo de curso nesse nível de ensino, e desses, apenas cerca de $3,5 \%$ estava nas Universidades públicas.

A predominância do ensino superior privado, tanto em relação ao número de alunos atendidos, quanto ao número de instituições, tem sido uma característica do quadro atual da educação superior brasileira. De acordo com o Censo do Ensino Superior (MEC/INEP), no ano de 2003, foram registradas 3.936.933 matrículas, em cursos de graduação presenciais e a distância, sendo 1.176.174 em IES públicas, e 2.760.759 em IES privadas, o que corresponde, respectivamente, a $29,9 \%$ (setor público) e $70,1 \%$ (setor privado), do total de matrículas presenciais e a distância por setor. 
Analisando o período que vai de 2003 a 2010 (dois governos de Lula da Silva), verifica-se um crescimento de $62 \%$ no conjunto de alunos matriculados em cursos presenciais e a distância no ensino superior brasileiro; observa-se, no entanto, que, no setor privado, esse crescimento foi de $71,5 \%$, quase o dobro que o apresentado pelo setor público, que cresceu $39,7 \%$. Em relação ao governo Dilma Rousseff, apresentamos os dados referentes ao ano de 2012, no entanto, considerando que a política adotada é a mesma do governo anterior, faremos uma análise da série histórica do período de 2003 a 2012.

No período de 2003 a 2012, observa-se o seguinte: as IES expandiram 30,0\%, sendo que as privadas cresceram $27,1 \%$ e as públicas, $46,9 \%$. É importante destacar que, a partir do ano de 2007, “o processo de mercantilização do ensino superior brasileiro vem adquirindo novos contornos" (CHAVES, 2010), com a criação de redes de empresas por meio da compra e/ou fusão de IES privadas do país, por empresas nacionais e internacionais de ensino superior, e pela abertura de capitais dessas nas bolsas de valores. Esse processo tem contribuído para a formação de Universidades gigantes, reduzindo-se a expansão do número de IES (de 2010 a 2012 foram criadas apenas 12 novas IES no setor privado) sem, no entanto, reduzir o número de matrículas, cuja expansão, no período, apresentou o percentual de $86,2 \%$, enquanto no setor público, mesmo com a expansão no número de IES, o aumento das matrículas foi inferior $(61,3 \%)$, como pode ser observado na Tabela 1 a seguir.

TABELA 1 - Número de Instituições de Educação Superior, matrículas e funções docentes por categoria administrativa. Brasil. 2003-2012.

\begin{tabular}{c|c|c|c|c|c|c|c|c|c}
\hline \multirow{2}{*}{ Ano } & \multicolumn{3}{|c|}{ Instituições } & \multicolumn{3}{c|}{ Matrículas (1) } & \multicolumn{3}{c}{ Funções Docentes (2) } \\
\cline { 2 - 10 } & Total & Pública & Privada & Total & Pública & Privada & Total & Pública & Privada \\
\hline $\mathbf{2 0 0 3}$ & 1.859 & 207 & 1.652 & 3.936 .933 & 1.176 .174 & 2.760 .759 & 268.816 & 95.863 & 172.953 \\
& & & & & & & & & \\
$\mathbf{2 0 1 0}$ & 2.378 & 278 & 2.100 & 6.379 .299 & 1.643 .298 & 4.736 .001 & 366.882 & 140.742 & 226.140 \\
$\mathbf{2 0 1 2}$ & 2.416 & $\mathbf{3 0 4}$ & $\mathbf{2 . 1 1 2}$ & 7.037 .688 & 1.897 .376 & 5.140 .312 & 378.939 & 160.374 & 218.565 \\
\hline $\begin{array}{c}\Delta \% \\
\mathbf{2 0 0 3 - 2 0 1 0}\end{array}$ & $\mathbf{2 7 , 9}$ & $\mathbf{3 4 , 3}$ & $\mathbf{2 7 , 1}$ & $\mathbf{6 2 , 0}$ & $\mathbf{3 9 , 7}$ & $\mathbf{7 1 , 5}$ & $\mathbf{3 6 , 5}$ & $\mathbf{4 6 , 8}$ & $\mathbf{3 0 , 8}$ \\
\hline $\begin{array}{c}\Delta \% \\
\mathbf{2 0 0 3 - 2 0 1 2}\end{array}$ & $\mathbf{3 0 , 0}$ & $\mathbf{4 6 , 9}$ & $\mathbf{2 7 , 8}$ & $\mathbf{7 8 , 8}$ & $\mathbf{6 1 , 3}$ & $\mathbf{8 6 , 2}$ & $\mathbf{4 1 , 0}$ & $\mathbf{6 7 , 3}$ & $\mathbf{2 6 , 4}$ \\
\hline
\end{tabular}

Fonte: MEC/INEP/DEAES, 2003, 2010, 2012.

Notas: (1) Matrículas em cursos presenciais e a distância

(2) Funções docentes em exercício e afastados

É importante ressaltar que o aumento das funções docentes, tanto no setor público, quanto no setor privado, não se deu na mesma proporção que as matrículas. Os dados da Tabela 1 demonstram que, no período de 2003 a 2010, as matrículas cresceram 62\%, enquanto que as funções docentes foram aumentadas em 36,5\%, o que nos possibilita afirmar que a política adotada foi a de expandir a oferta da educação superior no país, intensificando o trabalho docente, em especial no setor privado, cuja expansão das matrículas registrou um 
total de $71,5 \%$ no período, enquanto que as funções docentes tiveram um crescimento de menos da metade, ou seja, 30,8\%.

Os dados acima revelam, ainda, que a maior concentração de Instituições da Educação Superior ocorre no setor privado. De 2.378 instituições registradas, em 2010 (final do governo Lula), 278 eram públicas e 2.100, privadas. Analisando o período de 2003 a 2010, observa-se uma expansão de $27,9 \%$, sendo que o setor público registrou um maior percentual de expansão, com 34,3\%, e o setor privado expandiu 27,1\%. Ressalta-se, no entanto, que a expressiva maioria das Instituições está no setor privado, registrando 88,3\% das IES em 2010.

A predominância do setor privado na oferta do ensino superior no Brasil teve início nos governos da ditadura militar (CHAVES, 2015) e tem sido acentuada pela política privatista adotada pelo governo federal, materializada por uma série de medidas, tais como: isenções tributárias, isenção do pagamento do salário-educação, bolsas de estudo para alunos carentes via Fundo de Financiamento ao Estudante de Ensino Superior (FIES) ${ }^{\mathrm{ii}}$, empréstimos financeiros a juros subsidiados pelo Banco Nacional de Desenvolvimento Econômico e Social-BNDES, o Programa Universidade para Todos - PROUNI ${ }^{\mathrm{iii}}$, entre outras formas de estímulo ao setor privado, como será demonstrado em seguida.

Essa política de expansão do setor privado mercantil traz repercussões diretas para o trabalho docente, uma vez que a contratação de novos docentes para atender essa expansão não tem acompanhado o mesmo ritmo das matrículas. Os dados expostos na Tabela 1, mostram que no período de 2003 a 2012 (dos governos Lula e Dilma) as funções docentes expandiram $41 \%$, sendo que o setor público apresentou um percentual de expansão maior que o privado, $67,3 \%$ e 26,4\%, respectivamente. Comparando com a expansão das matrículas no mesmo período, observa-se que essa expansão nas funções docentes no setor privado foi muito inferior ao crescimento das matrículas nas IES desse setor que registrou um crescimento de $86,2 \%$, ou seja, um terço. Fica, assim, evidente que a política de expansão adotada no país está vinculada à intensificação do trabalho docente.

Esses dados demonstram que os sucessivos governos do Brasil (Fernando Henrique Cardoso, Lula e Dilma, seguem a mesma política de ajuste fiscal do Estado, definida pelos organismos multilaterais, em especial, o Banco Mundial, segundo o qual a expansão do ensino superior deve ser feita sem aumentar os gastos públicos. Como consequência, o trabalhador docente que atua nesse nível de ensino, tem seu trabalho intensificado, tanto no setor privado, cuja lógica é o lucro, como no setor público.

Outro aspecto significativo para a análise da política implementada para a educação superior no Brasil, refere-se à questão do financiamento público para esse nível de ensino. A política de ajuste fiscal, materializada por meio de reformas estruturais no Estado brasileiro, e na reconfiguração da educação superior como serviço não exclusivo do Estado, ou seja, como 
um serviço público não estatal, foi adotada no país a partir de 1995, com o Plano Diretor da Reforma do Estado ${ }^{\text {iv }}$. (BRESSER-PEREIRA; SPINK, 1998) Trata-se, de fato, da implantação de um Estado economicista e empresarial-gerencialista, em que a satisfação das demandas do mercado, e de sua lógica da competição, ocupam lugar de destaque.

A redução dos investimentos públicos, e a defesa da diversificação das fontes de financiamento, foram centrais na reforma da educação superior adotada no Brasil. Essa reforma cumpre as orientações do Banco Mundial, como se evidencia no relatório:

\begin{abstract}
[...] maior autonomia institucional é a chave para o êxito da reforma do ensino público superior, especialmente a fim de diversificar e utilizar os recursos mais eficientemente (...). A experiência demonstra que se quer que as instituições estatais melhorem sua qualidade e eficiência, os governos deverão efetuar reformas importantes no financiamento a fim de mobilizar mais recursos privados para o ensino superior em instituições estatais (...) de várias maneiras: mediante a participação dos estudantes nos gastos; arrecadação de recursos de ex-alunos; utilização de fontes externas; realização de outras atividades que gerem receitas. (grifos nossos). (BANCO MUNDIAL, 1995, p. 44 e 69)
\end{abstract}

Essa tese fundamenta-se no argumento de que o conhecimento propiciado pelo ensino superior deve ser visto como um investimento produtivo (pois garante ganhos), um bem privado, ou uma mercadoria de interesse individual negociado no mercado de trocas. Isso fortalece a ideia de que o Estado deve se afastar da manutenção desse nível de ensino, uma vez que a educação superior passa a ser considerada como um serviço público não exclusivo do Estado e competitivo.

De acordo com Amaral (1999), apesar do discurso oficial de que o governo investe muito dinheiro nas Universidades públicas, de fato, os gastos com as Instituições Federais de Ensino Superior representam apenas $0,67 \%$ do PIB $^{v}$. Desses, cerca de $0,35 \%$ correspondem ao pagamento de aposentados e pensionistas, incluindo, também, a manutenção dos hospitais universitários que, hoje, na maioria das cidades brasileiras, são responsáveis pelo atendimento da população pobre. Essa situação leva as universidades a cumprirem um papel social importante, mas à custa de utilizar parte expressiva de seu orçamento no financiamento dessas atividades, acentuando sua crise financeira. No item a seguir, aprofundaremos essa questão.

\title{
3 A POLÍTICA DE FINANCIAMENTO DA EDUCAÇÃO SUPERIOR NO BRASIL
}

A análise do financiamento público com as políticas sociais no país é de grande relevância para a compreensão do modelo adotado pelos sucessivos governos neoliberais. A tabela 2, exposta a seguir, apresenta o percentual de execução do Orçamento Geral da União em políticas sociais, com ênfase para educação, saúde, previdência e assistência social, no período de 2003 a 2012. Na primeira coluna, demonstramos o percentual de gastos com o pagamento/refinanciamento da dívida pública para que possamos comparar com os demais gastos sociais.

\begin{tabular}{l|c|c|c|c|c|c|}
\hline (C) ETD - Educ. temat. digit. & Campinas, SP & v.17 & n. 2 & p.427-441 & maio/ago. 2015 & ISSN 1676-2592
\end{tabular} 
TABELA 2 - Execução do Orçamento da União - 2003-2012

\begin{tabular}{|c|c|c|c|c|c|c|}
\hline & & & & & \multicolumn{2}{|c|}{ Despesas em \% } \\
\hline ANO & $\begin{array}{c}\text { DÍVIDA } \\
\text { PÚBLICA }^{1}\end{array}$ & PREVIDÊNCIA & SAÚDE & EDUCAÇÃO & $\begin{array}{l}\text { ASSISTÊNCIA } \\
\text { SOCIAL }\end{array}$ & $\begin{array}{c}\text { OUTRAS } \\
\text { DESPESAS }\end{array}$ \\
\hline 2003 & 61,66 & 16,87 & 2,97 & 1,52 & 0,92 & 16,06 \\
\hline 2004 & 57,31 & 18,55 & 3,39 & 1,49 & 1,53 & 17,72 \\
\hline 2005 & 59,39 & 17,47 & 3,10 & 1,31 & 1,45 & 17,28 \\
\hline 2006 & 56,65 & 18,57 & 3,16 & 1,49 & 1,86 & 18,27 \\
\hline 2007 & 52,21 & 19,95 & 3,42 & 1,71 & 2,09 & 20,62 \\
\hline 2008 & 47,17 & 20,32 & 3,75 & 2,01 & 2,40 & 24,34 \\
\hline 2009 & 48,20 & 20,80 & 3,72 & 2,31 & 2,48 & 22,50 \\
\hline 2010 & 44,91 & 22,11 & 3,92 & 2,88 & 2,74 & 23,43 \\
\hline 2011 & 44,98 & 21,98 & 4,05 & 2,99 & 2,85 & 23,15 \\
\hline 2012 & 43,98 & 22,47 & 4,17 & 3,34 & 3,15 & 22,9 \\
\hline $\begin{array}{c}\Delta 2003- \\
2012\end{array}$ & $-28,67$ & 33,15 & 40,20 & 120,62 & 242,30 & 42,54 \\
\hline
\end{tabular}

Fonte: Senado federal (Portal Orçamento - SIGA Brasil). Elaboração do autor com base nos demonstrativos (2003 - 2012) da Execução Orçamentária por Função e por Subfunção e Execução Orçamentária por Grupo Natureza da Despesa - GND.

(1) Inclui as despesas com Juros e encargos, amortização e refinanciamento.

Os dados evidenciam que o governo federal tem comprometido mais da metade do orçamento da União com o pagamento dos serviços da dívida, em média, cerca de $50 \%$ do orçamento executado, enquanto à educação, têm sido destinados, em média, apenas $2 \%$ dos recursos totais arrecadados (considerando impostos, contribuições e taxas).

Apesar de o pagamento com os serviços da dívida apresentar uma redução de $28,67 \%$, no período de 2003 a 2012, os dados acima evidenciam que essa rubrica continua sendo a prioridade da política dos governos Lula da Silva e Dilma. Em 2012, 43,98\% dos recursos do orçamento da União foram comprometidos com esse pagamento, enquanto à educação foram destinados apenas 3,34\% no mesmo ano, apesar de o orçamento executado para a educação ter obtido um acréscimo de $120 \%$ no período.

Os gastos com as políticas sociais que obtiveram maior expansão no período foram com assistência social, registrando um percentual de aumento de $242,3 \%$, o que evidencia a política adotada de concessão de bolsas a famílias em situação de risco, do Programa Bolsa Família,

Outro dado importante para a análise do financiamento da educação no país refere-se à comparação da execução do orçamento da União com o Produto Interno Bruto - PIB, uma vez que é uma das referências para comparações internacionais. 
Os dados a seguir, expostos na Tabela 3, evidenciam que as despesas com a função educação, no início do governo Lula (2003), comprometeu apenas 0,84\% do PIB, e representou $1,62 \%$ das despesas totais da União com todas as funções. Observa-se, ainda, que até o ano de 2006 (primeiro mandato do governo Lula), se manteve no mesmo patamar, sendo que em 2004 caiu para 0,75\% do PIB, em 2005 conservou o mesmo índice e, em 2006, ficou em $0,83 \%$ do PIB. Em relação às despesas totais da União, a Função Educação também se manteve, até o ano de 2006, no mesmo patamar que em 2003.

TABELA 3. Execução das despesas da União na função Educação como percentual do PIB e da despesa total da União (todas as funções) - 2003-2012.

\begin{tabular}{|c|c|c|c|c|c|}
\hline \multirow[b]{2}{*}{ ANO } & \multirow[b]{2}{*}{$\begin{array}{l}\text { PIB } \\
(A)\end{array}$} & \multirow{2}{*}{$\begin{array}{c}\text { DESPESAS TOTAIS } \\
\text { DA UNIÃO } \\
\text { (TODAS AS } \\
\text { FUNÇÕES) } \\
\text { (B) }\end{array}$} & \multicolumn{3}{|c|}{ FUNÇÃO EDUCAÇÃO } \\
\hline & & & $\begin{array}{l}\mathbf{R} \$ \\
\text { (C) }\end{array}$ & $\begin{array}{c}\% \\
(\mathrm{C}) /(\mathrm{A})\end{array}$ & $\begin{array}{c}\% \\
\text { (C) /(B) }\end{array}$ \\
\hline 2003 & 2.830 .244 .611 .834 & 1.459 .283 .264 .865 & 23.685 .085 .712 & $\mathbf{0 , 8 4}$ & 1,62 \\
\hline 2004 & 3.014.233.500.088 & 1.409.973.049.902 & 22.562 .802 .345 & $\mathbf{0 , 7 5}$ & 1,60 \\
\hline 2005 & 3.138 .551 .177 .362 & 1.617.760.926.538 & 23.661 .041 .143 & 0,75 & 1,46 \\
\hline 2006 & 3.361.917.019.921 & 1.679.495.955.844 & 27.904 .298 .146 & $\mathbf{0 , 8 3}$ & 1,66 \\
\hline 2007 & 3.624 .245 .672 .405 & 1.666.580.463.908 & 33.165 .015 .454 & $\mathbf{0 , 9 2}$ & 1,99 \\
\hline 2008 & 3.881 .341 .133 .240 & 1.611 .367 .125 .378 & 36.162 .258 .808 & $\mathbf{0 , 9 3}$ & 2,24 \\
\hline 2009 & 3.978.724.427.301 & 1.739.626.036.855 & 45.050 .795 .824 & 1,13 & 2,59 \\
\hline 2010 & 4.383 .492 .384 .005 & 1.749 .812 .589 .598 & 56.393 .268 .281 & 1,29 & 3,22 \\
\hline 2011 & 4.517 .121 .642 .203 & 1.828 .246 .848 .146 & 63.732 .206 .384 & 1,41 & 3,49 \\
\hline 2012 & 4.548.371.151.157 & 1.900 .738 .748 .291 & 74.979 .572 .967 & 1,65 & 3,94 \\
\hline $\begin{array}{c}\Delta 2003- \\
2012\end{array}$ & 60,7 & 30,3 & 216,6 & & \\
\hline
\end{tabular}

Fonte: Banco Central; Senado Federal (Portal Orçamento - SIGA Brasil). Elaboração do autor com base nos demonstrativos (2003 - 2012) da Execução Orçamentária por Função e por Subfunção.

Nota: valores atualizados a preços de abril de 2013 (IPCA)

Os dados evidenciam, ainda, que no segundo mandato do governo Lula da Silva, e nos dois primeiros anos do governo de Dilma Rousseff, houve um aumento percentual significativo das despesas com a função educação. No período total de análise (2003 a 2012) os dados mostram que as despesas com a função educação ampliaram em 216,6\%, enquanto o PIB aumentou em $60,7 \%$ e as despesas totais da União com todas as funções cresceram $30,3 \%$. Mesmo com esse significativo aumento nas despesas da educação, em comparação com o PIB, o percentual ainda é bastante pequeno (1,65\%), e se considerarmos todos os recursos públicos nesse setor (incluindo os gastos dos Estados, municípios e distrito federal), não ultrapassa os $5 \%$ do PIB, o que ainda está muito distante do que foi estabelecido no novo Plano Nacional da Educação, de utilizar, no mínio 10\% do PIB em educação pública.

Ao se analisar o financiamento da educação superior pública brasileira, os problemas se acentuam. Se considerarmos os recursos destinados a despesas da União com as Universidades federais, no período de 2003 a 2012, e o que representam em relação às 
despesas com a função Educação, e como percentual dos recursos destinados ao MEC, observa-se uma redução percentual a cada ano, como pode ser constatado na Tabela 4 a seguir:

TABELA 4 - Execução das despesas da União com as Universidades federais, como percentual das despesas com a função Educação e dos recursos destinados ao MEC - 2003-2012.

\begin{tabular}{|c|c|c|c|c|c|}
\hline \multirow[t]{2}{*}{ ANO } & \multirow{2}{*}{$\begin{array}{c}\text { FUNÇÃO } \\
\text { EDUCAÇÃOO } \\
\text { R\$ (A) }\end{array}$} & \multirow{2}{*}{$\begin{array}{c}\text { MEC } \\
\mathbf{R} \$(\mathbf{B})\end{array}$} & \multicolumn{3}{|c|}{$\begin{array}{c}\text { DESPESAS COM AS UNIVERSIDADES } \\
\text { FEDERAIS }\end{array}$} \\
\hline & & & $\mathbf{R} \$(C)$ & $\begin{array}{c}\% \\
\text { C/A }\end{array}$ & $\begin{array}{c}\% \\
\text { C/B }\end{array}$ \\
\hline 2003 & 23.685 .085 .712 & 30.166 .243 .335 & 15.266 .361 .051 & 64,46 & 48,09 \\
\hline 2004 & 22.562 .802 .345 & 28.547.945.959 & 16.786 .197 .485 & $\mathbf{7 4 , 4 0}$ & 58,46 \\
\hline 2005 & 23.661 .041 .143 & 29.275 .018 .860 & 17.037.693.266 & 72,01 & 55,40 \\
\hline 2006 & 27.904 .298 .146 & 33.946 .459 .001 & 20.613 .652 .006 & 73,87 & 64,18 \\
\hline 2007 & 33.165 .015 .454 & 39.102 .181 .028 & 21.917 .028 .624 & 66,08 & 54,92 \\
\hline 2008 & 36.162 .258 .808 & 42.259 .568 .349 & 22.420 .138 .903 & 62,00 & 54,32 \\
\hline 2009 & 45.050 .795 .824 & 51.338.565.326 & 28.191 .093 .767 & 62,58 & 53,00 \\
\hline 2010 & 56.393 .268 .281 & 63.035 .310 .802 & 30.844 .449 .160 & 54,70 & 49,52 \\
\hline 2011 & 63.732 .206 .384 & 69.813.649.163 & 33.242 .453 .346 & 52,16 & 47,70 \\
\hline 2012 & 74.979 .572 .967 & 78.389 .442 .149 & 29.987.452.200 & 39,99 & 46,99 \\
\hline
\end{tabular}

Fonte: Senado Federal (Portal Orçamento - SIGA Brasil). Elaboração do autor com base nos demonstrativos (2003 - 2012) da Execução Orçamentária por Função e por Subfunção, Execução Orçamentária por Órgão (MEC) e Execução Orçamentária por Órgão e Unidades Orçamentárias.

Nota: valores atualizados a preços de abril de 2013 (IPCA)

Os dados mostram que as despesas com as Universidades federais representaram, em 2003, 64,46\% das despesas com a função educação e, em 2012, foram reduzidas para 39,99\% dessas despesas. Considerando os recursos da União destinados ao Ministério da Educação, observa-se que, em 2003, os gastos com todas as Universidades representaram 48,09\% das despesas com o MEC e, em 2012, 46,9\%.

Pode-se, assim, afirmar que a política de ajuste fiscal implementada nos dois governos de Lula da Silva, e no primeiro governo de Dilma Rousseff, vem sendo materializada por meio da redução dos recursos públicos para as Universidades federais, ao analisarmos os gastos da União com a função Educação, e em relação ao total das despesas com o MEC. Concluímos que o discurso do governo de que as IFEs teriam recebido mais recursos nos últimos anos, desconsidera o aumento da receita da União, bem como a expansão das matrículas ocorrida nesse período, concomitantemente com a criação de novas Universidades e campi.

Ressaltamos, ainda, que o governo vem adotando uma política de contingenciamento de recursos ao longo de cada ano, concentrando a execução dos programas e ações no final 
do ano, com a finalidade de garantir o superávit primário $^{v i}$, fazendo reserva para assegurar o pagamento de parcela dos serviços da dívida pública, sinalizando aos credores as boas intenções do governo em economizar.

Sobre essa questão, é interessante destacar que, ao mesmo tempo em que o governo adota uma política de contenção de gastos com as Universidades públicas federais, tem estimulado o crescimento do ensino superior privado por meio de políticas de isenções fiscais que beneficiam esse setor, como pode ser observado nos dados a seguir, expostos na Tabela 5.

TABELA 5 - Renúncia Tributária Vinculada à Função Educação, de 2006 a 2013

(Valores em Milhões de R\$)

\begin{tabular}{|c|c|c|c|c|c|c|c|c|c|}
\hline $\begin{array}{l}\text { Tipo de Renúncia de } \\
\text { Receita Tributária }\end{array}$ & 2006 & 2007 & 2008 & 2009 & 2010 & 2011 & 2012 & 2013 & $\%$ \\
\hline \multicolumn{10}{|l|}{ Despesas com } \\
\hline Educação - IRPF & 1.554 & 1.570 & 2.145 & 1.321 & 1.914 & 1.046 & 4.980 & 2.119 & 25,98 \\
\hline \multicolumn{10}{|l|}{ Entidades Sem Fins } \\
\hline Lucrativos - Educação & 1.407 & 2.375 & 2.823 & 3.200 & 4.001 & 3.576 & 3.771 & 4.164 & 51,07 \\
\hline \multicolumn{10}{|l|}{ Livros técnicos e } \\
\hline científicos & - & - & - & 213 & 508 & 447 & 493 & 548 & 6,72 \\
\hline \multicolumn{9}{|l|}{ Transporte Escolar } & 1,20 \\
\hline PROUNI & 329 & 156 & 403 & 622 & 774 & 632 & 908 & 929 & 11,40 \\
\hline \multicolumn{10}{|l|}{$\begin{array}{l}\text { Doações a Instituições } \\
\text { de Ensino e Pesquisa }\end{array}$} \\
\hline \multicolumn{9}{|l|}{ Total Anual } & 100,00 \\
\hline $\begin{array}{l}\text { Fonte: Demonstrativos } \\
\text { (http://www.receita.fazenda }\end{array}$ & $\begin{array}{l}\text { de } g \\
\text { ov.br.) }\end{array}$ & & butários & $(20$ & -2013) & & B. & isponí & \\
\hline
\end{tabular}

Nota: 1. Valores em R\$ (milhões), atualizados pelo IPCA/IBGE, a preços de jan./2015.

2. ( - ) indica a ausência da renúncia de receita no exercício financeiro.

Os dados mostram que as renúncias para entidades sem fins lucrativos representam mais de 50\% do total de renúncias tributárias para a educação no período de 2006 a 2013 . Em seguida, as despesas com educação descontadas no Imposto de Renda Pessoa Física (IRPF) representam uma renúncia de $26 \%$ em média do total de renúncias fiscais. É possível identificar, ainda, que a renúncia de impostos para o PROUNI vem aumentando a cada ano e, em 2013, representava quase $12 \%$ do montante de renúncia tributária vinculada à educação. Para Gemaque e Santos Filho (2011, p. 212), "as renúncias tributárias na área de educação têm beneficiado muito mais a mercantilização do ensino e a ampliação do capital privado do que a redução de desigualdades sociais". Apesar do discurso ideológico propalado pelo governo federal de que o PROUNI é um programa destinado a inserir os pobres no ensino superior, na prática, tornou-se mais um dos mecanismos de indução da expansão do setor privado. 
Outra política que tem beneficiado o setor privado de educação superior é a do FIES. Os dados a seguir mostram a evolução dos valores públicos destinados aos empréstimos a estudantes de IES privadas.

TABELA 6 - Evolução dos empréstimos FIES - 2000-2013

\begin{tabular}{cc} 
& Valores em R \$ Milhões \\
\hline ANO & TOTAL FIES \\
$\mathbf{2 0 0 0}$ & 2.147 \\
$\mathbf{2 0 0 1}$ & 1.100 \\
$\mathbf{2 0 0 2}$ & 1.316 \\
$\mathbf{2 0 0 3}$ & 1.342 \\
$\mathbf{2 0 0 4}$ & 1.238 \\
$\mathbf{2 0 0 5}$ & 1.306 \\
$\mathbf{2 0 0 6}$ & 1.455 \\
$\mathbf{2 0 0 7}$ & 1.491 \\
$\mathbf{2 0 0 8}$ & 1.700 \\
$\mathbf{2 0 0 9}$ & 1.923 \\
$\mathbf{2 0 1 0}$ & 2.276 \\
$\mathbf{2 0 1 1}$ & 3.053 \\
$\mathbf{2 0 1 2}$ & 6.290 \\
$\mathbf{2 0 1 3}$ & 8.372 \\
TOTAL & $\mathbf{3 5 . 0 0 9}$ \\
\hline
\end{tabular}

Fonte: Lei Orçamentária (2000-2013). Portal Orçamento - Senado Federal.

Notas: 1. Valores atualizados em Jan/2015, pelo IPCA.

2. Créditos orçamentários autorizados.

No período analisado, 2000 a 2013, o montante de recursos destinados ao FIES chegou a mais de 35 bilhões de reais (em valores atualizados). Os dados evidenciam que os dois últimos anos (2012 e 2013) apresentam o maior aporte de recursos para esse financiamento. Essa política tem beneficiado as instituições do setor privado que se expandem a cada ano, tornando o Brasil, o segundo país mais privatizado da América Latina (só perde para o Chile). Com a injeção dos recursos do FIES, as IES privadas têm garantido o pagamento das mensalidades de uma grande parcela de estudantes, o que favorece a expansão desse setor.

\section{CONSIDERAÇÕES FINAIS}

A política de financiamento adotada no país vincula-se à efetiva reforma da educação superior no Brasil, posta em prática após a crise do Estado de Bem-Estar Social na Europa e do Nacional-Desenvolvimentismo na América Latina, e que faz parte das transformações administrativo-gerenciais do Estado. Estas visaram (e visam) ajustar as ações do Estado, adequando-o à nova ordem internacional, cuja centralidade se configura, entre outros, no crescente aumento dos valores orçamentários destinados à acumulação do capital, e na simétrica e proporcional redução de gastos com as políticas sociais. 
O processo de transformação e readequação do Estado à "nova ordem" efetiva-se por meio de medidas reguladoras destinadas a aumentar a acumulação e concentração do capital, a desonerá-lo e a maximizar o lucro. Entre tais medidas, destaca-se a da transferência do financiamento de grande parte das ações de Estado para a responsabilidade da sociedade civil. Para justificá-la, alega-se que a solução da crise (financeira) do Estado requer a redução do déficit causado por supostos excessivos gastos públicos com o pessoal e as políticas sociais. Em decorrência, recorre-se à privatização para reduzir a presença do Estado.

Para o implemento dessa reforma na educação superior, o governo federal passou a incentivar a expansão tanto do setor público quanto do setor privado. Pode-se afirmar, no entanto, que a expansão das instituições públicas se deu com contenção de gastos, enquanto que para o setor privado o estudo evidenciou que o governo adotou uma política de liberalização e de estímulo, em especial, por meio da criação do PROUNI e do FIES.

O estudo apontou também que a política de financiamento adotada nos governos de Lula da Silva e Dilma Rousseff, fundamenta-se na lógica produtivista, com racionalidade de recursos para viabilizar o ajuste fiscal em detrimento do investimento em políticas sociais. Os dados evidenciaram que a propaganda difundida pelos dois governos petistas, de terem aumentado os investimentos em educação, é facilmente desmontada por meio de análise dos estudos elaborados pelo próprio órgão oficial do MEC, o INEP.

Em síntese, pode-se afirmar que o comportamento do governo em relação ao investimento na educação, em especial, na educação superior, atende as orientações dos organismos multilaterais financeiros, em especial as do Banco Mundial, que defendem entre outras medidas: "disciplina fiscal", priorização dos gastos públicos em áreas de "alto risco" e privatização dos serviços sociais. Em relação à educação superior, explicita-se a necessidade de esta ser reestruturada com vistas à adoção do modelo de gestão gerencial, com diversificação das formas e fontes de financiamento, além da criação de instrumentos ditos de avaliação destinados a medir resultados quantitativos. Isto é, sob o discurso da lógica gerencialista, os organismos internacionais buscam novos mercados para a venda de produtos e serviços e, para tanto, pressionam o governo para liberar exploração comercial do ensino.

É preciso reverter essa lógica para que a população possa, de fato, ter acesso a uma educação pública e de qualidade em todos os níveis. Levando em consideração o fato de que, em especial nos níveis médio e superior, o sistema educacional público precisaria ser consideravelmente expandido e ter sua qualidade resgatada, não haverá essa possibilidade se não tiver um importante aporte adicional de verbas públicas, elevando o montante para níveis mais próximos aos internacionais, em particular de países que estão despontando como desenvolvimentistas, o que significaria, no mínimo, dobrá-los, para atingir 10\% do PIB. 


\section{REFERÊNCIAS}

AMARAL, Nelson Cardoso Financiamento da educação superior: estado x mercado. São Paulo: Cortez; Piracicaba, SP: UNIMEP, 2003. 214p.

AMARAL, Nelson Cardoso. Crise no financiamento das instituições federais de ensino superior. In: TRINDADE, Hélgio. (Org.) Universidade em ruínas na república dos professores. Petrópolis: Vozes, 1999. p. 191-200.

BIRD/BANCO MUNDIAL. La ensanñanza superior: las lecciones derivadas de la experiência. (El Desarrollo en la práctica). Washington, D.C: BIRD/Banco Mundial, 1995.

BRESSER-PEREIRA, Luis (Org.); Carlos; SPINK, Peter (Org.). Reforma do Estado e administração pública gerencial. Rio de Janeiro: Fundação Getúlio Vargas, 1998. 314p.

BRASIL. Lei no 10.260, de 12 de julho de 2001. Dispõe sobre o Fundo de Financiamento ao Estudante de Ensino Superior - FIES. Diário Oficial da União. 13 jul. 2001. Disponível em: < http://goo.gl/jQ0LzF>. Acesso em: 20 mai. 2014.

BRASIL. Lei ${ }^{\circ} 11.096$, de 13 de janeiro de 2005. Institui o Programa Universidade para Todos - PROUNI, regula a atuação de entidades beneficentes de assistência social no ensino superior; altera a Lei $\mathrm{n}^{\circ} 10.891$, de 9 de julho de 2004, e dá outras providências. Diário Oficial da União, Brasília, DF, 14 jan. 2005c. Disponível em: < http://goo.gl/jBkn0e>. Acesso em: 05 jun. 2011.

BRASIL. Lei orçamentária de 2000 a 2013. Disponível em: 〈 http://goo.gl/ihWn4A > . Acesso em 10 jan. 2015.

BRASIL. Sinopse estatística do censo da educação superior: 2003 a 2012. Brasília, DF: MEC. Disponível em: <http://www.inep.gov.br/superior/censosuperior/sinopse/default.asp>. Acesso em: 10 mai. 2014.

BRASIL. Secretaria da Receita da Fazenda do Brasil (SRFB). Demonstrativos de gastos tributários - 2006 a 2013. Disponíveis em: 〈 http://goo.gl/X1VnZh〉. Acesso em 10 jan. 2015.

CHAVES, Vera Lúcia Jacob; AMARAL, Nelson Cardoso. A educação superior no Brasil: os desafios da expansão e do financiamento os desafios da expansão e do financiamento e comparações com outros países. Revista Educação em Questão, v. 51, n. 37, jan/abr. 2015, p. 95-120. Disponível em: <http://goo.gl/90D2Ua>. Acesso em: 18 jul. 2015. ISSN: 19811802.

CHAVES, Vera Lúcia Jacob. Expansão da privatização/mercantilização do ensino superior brasileiro a formação dos oligopólios. Educação \& Sociedade, Campinas, v. 31, n.111, abr./jun. 2010, p. 481-500. Disponível em: 〈http://goo.gl/YD4eAk〉. Acesso: 20 fev. 2015. ISSN: $1678-4626$. 
CHAVES, Vera Lúcia Jacob. As feições da privatização do público na educação superior brasileira: o caso da UFPA. 2005. 436f. Tese (Doutorado em Educação) - Faculdade de Educação, Universidade Federal de Minas Gerais, Belo Horizonte, MG, 2005. Disponível em: <http://goo.gl/Se0SH7>. Acesso em: 18 mai. 2015.

GEMAQUE, Rosana Maria Oliveira; SANTOS FILHO, João Ribeiro. Renúncia tributária e financiamento da educação superior: favorecimento do Ensino Privado em detrimento do Público. In: CHAVES, Vera Lúcia Jacob (Org.); CABRITO, Belmiro. (Org.). Políticas de acesso e financiamento da educação superior no Brasil e em Portugal: tendências actuais. Lisboa: EDUCA, 2011. p. 195-214.

OLIVEIRA, Marcos Marques de. A Política Governamental de Ciência e Tecnologia: da C\&T à CT\&I. In: NEVES, Lucia Maria Wanderley (Org.). O empresariamento da educação: novos contornos no Brasil dos anos 1990. São Paulo: Xamã, 2002. p.65-84.

\footnotetext{
i O texto apresenta resultados da Pesquisa "Política de Financiamento da Educação Superior no Brasil- uma análise dos Planos Nacionais de Educação" financiada pelo CNPq e pela CAPES.

ii O Fundo de Financiamento ao Estudante de Ensino Superior (FIES) foi instituído pela Lei no. 10.260 de 12 de julho de 2001, tendo como origem a MP no. 1.827 de 27 de maio de 1999.

iii O "Programa Universidade para Todos" - PROUNI foi instituído pela Lei no 11.096, de 13 de janeiro de 2005 e estende os benefícios fiscais para todas as IES privadas, em "troca" de preenchimento das "vagas ociosas" por alunos "carentes", afrodescendentes, portadores de necessidades especiais, indígenas, ex-presidiários.

iv O Plano Diretor da Reforma do Aparelho do Estado, publicado em novembro de 1995, apresenta os princípios básicos da Reforma do Estado brasileiro. Nesse plano, são definidas as atividades que devem ficar sob a responsabilidade direta do Estado, as que deve coordenar e/ou supervisionar e as que deve entregar para a iniciativa privada. (BRESSER PEREIRA; SPINK, 1998).

v Produto Interno Bruto (PIB) é um dos indicadores adotados em âmbito mundial para medir a soma da produção de bens e serviços ocorrida dentro de um país num determinado tempo.

vi Superávit primário significa que o governo gastou menos do que arrecadou de recursos, ou seja, representa a economia feita com as contas públicas, demonstrando a capacidade de reduzir gastos e, assim, garantir o pagamento da dívida pública junto aos credores.
}

\section{Como citar este documento:}

JACOB CHAVES, Vera Lúcia. Política de financiamento e a expansão da educação superior no Brasil: o público e o privado em questão. ETD - Educação Temática Digital, Campinas, SP, v. 17, n. 2, p. 427-441, ago. 2015. ISSN 1676-2592. Disponível em:

<http://periodicos.sbu.unicamp.br/ojs/index.php/etd/article/view/8635212>. Acesso em: 28 ago. 2015. 